\title{
Gestão de organizações cooperativas: o problema do portfólio em coo- perativảs agropecuárias do Rio Grande do Sul
}

\author{
Management of cooperative organizations: The problem of portfolio in agricultural \\ cooperatives in the state of Rio Grande do Sul
}

\begin{abstract}
Resumo
Este trabalho objetivou analisar o problema do portfólio e identificar as estratégias empregadas pelas cooperativas agropecuárias do Rio Grande do Sul (RS), a fim de minimizar esse problema decorrente dos direitos de propriedade difusos. A ferramenta para coleta dos dados consistiu em um roteiro semiestruturado e foram amostradas $10 \%$ das cooperativas agropecuárias do RS, estratificadas com base no porte e na atividade produtiva. O problema do portfólio apresentou maior incidência nas cooperativas que processam ou transformam a matéria-prima. Visando à redução do problema do portfólio, identificaram-se diferentes estratégias nas cooperativas analisadas: a escolha dos projetos de investimentos com base no mercado, a avaliação técnica dos projetos e investimentos, a opção pelo não crescimento da cooperativa, a composição do conselho de administração para evitar problemas de portfólio lateral.
\end{abstract}

Palavras-chave: Agronegócios. Economia rural. Cooperativismo agropecuário. Estratégias em cooperativas.

\begin{abstract}
This paper aimed to analyze the portfolio problem and to identify the strategies employed by the agricultural cooperatives in the state Rio Grande do Sul (RS), to minimize this problem due to the diffuse property rights. The tool for data collection consisted of a semi-structured interviews and it were sampled $10 \%$ of agricultural cooperatives from $R S$, stratified based on the size and productive activity. The portfolio problem presented higher incidence in the cooperatives that process or transform the raw material. In order to reduce the portfolio problem, different strategies were identified in the analyzed cooperatives, including: the choice of investment projects based on the market, the technical evaluation of projects and investments, the option for no growth of the cooperative, the composition of administration council to prevent the lateral portfolio problems.
\end{abstract}

Keywords: Agribusiness. Rural Economy. Agricultural cooperativism. Strategies in cooperatives.

Recebido: 12/04/2014 Aceito: 21/01/2015

Dieisson Pivoto ${ }^{1}$, Paulo Dabdab Waquil², Carlos Alberto Oliveira de Oliveira ${ }^{3}$, Giana de Vargas Mores ${ }^{4}$ e Vitor Francisco Dalla Corte $^{5}$

1,4 Universidade Federal do Rio Grande do Sul, Mestre em Agronegócios - dieissonpivoto@gmail.com / gimores@gmail.com

${ }^{2}$ Universidade Federal do Rio Grande do Sul, Mestre em Economia Rural - waquil@ufrgs.br

${ }^{3}$ FEPAGRO, Mestre em Agronegócios - carlos-oliveira@fepagro.rs.gov.br

${ }^{5}$ Vitor Francisco Dalla Corte, Mestre em Administração - vitordallacorte@gmail.com 


\section{Introdução}

$\mathrm{O}$ cooperativismo agropecuário brasileiro, especialmente no estado do Rio Grande do Sul (RS), enfrenta um momento de reflexão na relação cooperado-cooperativa, no processo de capitalização e de gestão das organizações. Muitas cooperativas agropecuárias do estado estão passando por crises financeiras e algumas delas em processo de liquidação. Os resultados de Pivoto et al. (2014) corroboram com essa informação, os quais evidenciam que mais de $50 \%$ (em um grupo de 45 cooperativas agropecuárias do RS estudadas) apresentaram um grau de endividamento superior a 3,30 em 2009. Esse índice representa o quanto a cooperativa está utilizando de recursos de terceiros para cada $R \$ 1,00$ de recursos próprios aplicados.

Um aspecto que pode ter relação com o alto grau de endividamento das cooperativas gaúchas refere-se aos problemas de gestão que surgem em função dos direitos de propriedades difusos nas cooperativas agropecuárias. Esses direitos existem, pois não há separação na cooperativa da parcela da estrutura e do capital que pertence a cada cooperado. Na literatura econômica, um desses problemas é denominado de problema do portfólio.

No caso de cooperativas agropecuárias, o problema do portfólio foi descrito pela primeira vez por Plunkett (2005). Para o autor, esse problema é endêmico da estrutura dos direitos de propriedade das organizações cooperativas. O mesmo surge devido à impossibilidade dos cooperados ajustarem o seu portfólio de ativos na cooperativa para corresponder com suas preferências de risco pessoal, devido a não transferência e liquidez, bem como pela falta de instrumentos financeiros de apreciação das cotas-partes nas cooperativas (COOK, 1995).

Com isso, subgrupos de cooperados tendem a fazer pressão na organização para reorganizar o portfólio de investimentos da cooperativa, mesmo que um portfólio de menor risco implique retornos mais baixos para a organização (COOK; ILIOPOULOS, 1998). Dessa forma, o problema do portfólio emerge pelo fato da cooperativa não ser capaz de alinhar as suas estratégias de investimento e negócios às dos cooperados, devido a sua estrutura dos direitos de propriedade.

Diante do exposto, este trabalho objetiva analisar o problema do portfólio e identificar as estratégias empregadas pelas cooperativas agropecuárias do Rio Grande do Sul para minimizar este problema. A maioria dos trabalhos relacionados ao cooperativismo agropecuário, como foco na governança e na gestão cooperativa, foi realizada em países do hemisfério Norte (Canadá, Estados Unidos e países da União Europeia) e, com isso, indagou-se sobre a presença e a intensidade do problema do portfólio no ambiente institucional do Rio Grande do Sul.

\section{Organização cooperativa sob a ótica da nova economia institucional}

O negócio cooperativo possui um conjunto de orientações que estabelecem a forma de relacionamento entre a cooperativa e os cooperados. Estas orientações são denominadas "princípios cooperativistas" e o tornam diferentes de outros empreendimentos econômicos. Estas diferenças são identificadas na finalidade da cooperativa, a forma de propriedade e de controle e como são distribuídas as sobras operacionais geradas.

De modo geral, podem-se elencar três princípios que distinguem uma cooperativa de outro empreendimento. O primeiro é o princípio do dono-usuário: os cooperados são proprietários e financiadores da cooperativa, sendo as mesmas pessoas que utilizam e se beneficiam de seus serviços. Por segundo, tem-se o princípio do usuáriocontrolador: os cooperados que controlam a cooperativa são as mesmas pessoas que utilizam e se beneficiam de seus serviços. O terceiro princípio é o do usuário-beneficiário: a finalidade da cooperativa é propiciar benefícios e ganhos aos usuários proporcionalmente à sua participação no negócio (VALADARES, 2001).

Em relação aos aspectos legais, a lei $n^{\circ} 5.764$ de 1971 distingue as cooperativas das demais sociedades pelas características: adesão voluntária; variabilidade do capital social, representado por cotas-partes; inacessibilidade de cotas-partes do capital a terceiros; singularidade de voto; quórum para funcionamento e deliberação da assembleia geral, baseada no número de associados e não no capital; retorno das sobras líquidas do exercício, proporcionalmente às operações realizadas pelo associado; indivisibilidade dos fundos de reserva; assistência técnica educacional e social; neutralidade política (BRASIL, 1971).

A Aliança Cooperativa Internacional (ACI) reconhece sete princípios do cooperativismo, fazendo com que as organizações tenham objetivos mais amplos do que a simples maximização do lucro. Os princípios são: associação voluntária e aberta; controle democrático dos membros; participação econômica dos membros; autonomia e independência; educação; treinamento e informação; intercooperação e preocupação com a comunidade (BIALOSKORSKI NETO, 2012). O controle democrático pelos cooperados confere características específicas para as organizações cooperativas, pois os direitos de controle não são proporcionais ao capital integralizado na cooperativa. $\mathrm{O}$ direito de controle do cooperado não varia de acordo com a sua cota de capital, mas sim corresponde a um voto por cooperado, independente do volume de capital que o mesmo possui na organização.

Em suma, pode-se concluir que as cooperativas diferem das demais organizações por dois motivos. O primeiro é que os cooperados são simultaneamente proprietários, usuários e consumidores dos seus produ- 
tos e serviços (COOK, 1995). O segundo motivo é que o direito ao controle não é vinculado ao direito às sobras. Essas especificidades, existentes na relação cooperadocooperativa, originam problemas na governança e, por consequência, na gestão dessas organizações que, se não consideradas pelos cooperados, diretores e gestores podem levar ao insucesso do empreendimento cooperativo.

\section{Organização cooperativa sob a ótica da nova economia institucional}

A economia neoclássica e a Nova Economia Institucional (NEI) são duas das principais escolas do pensamento econômico, que abordam as questões relacionadas à organização de uma firma. Na ótica neoclássica, a firma é vista como uma unidade técnica, na qual se produzem mercadorias de acordo com uma função de produção, sendo os fatores de produção alocados entre os diferentes usos e proporções por meio do mecanismo de preços. No entanto, essa teoria deixa uma lacuna, pois não se visualiza o que ocorre no interior da firma.

Na nova economia institucional, a firma é observada como um arranjo de diferentes contratos entre diversos agentes econômicos, no qual surgem custos que afetam os arranjos, a alocação de recursos e a forma como os bens e serviços são produzidos (BIALOSKORSKI NETO, 2012). A NEI não é uma abordagem oposta à neoclássica, mas sim um desenvolvimento teórico complementar, evidenciando que outras variáveis também são determinantes na alocação de recursos.

Os principais pensadores da NEI são Ronald Coase, Oliver Williamson e Douglass North. Commons (1931) foi pioneiro a destacar que a unidade econômica de análise deveria ser a transação, indicando que a firma não se caracteriza apenas como uma resposta às características tecnológicas e por questões como economia de escala e escopo.

Coase (1937) apresenta a noção dos custos de transação, sendo decorrentes do não funcionamento do mercado. $\mathrm{O}$ autor aponta que, quando os mercados funcionam, os custos de transação são nulos. Entretanto, demonstra que existem algumas situações em que o mercado autorregulado não é suficiente para garantir o melhor desempenho da sociedade. Os custos de transação são determinantes para a escolha da arquitetura organizacional e as estratégias adotadas pelas cooperativas.

Os teóricos da NEI discutem sobre o ambiente em que existem falhas de mercado, as quais comprometem o bom desempenho das transações. As falhas de mercado podem ser definidas, na visão tradicional, como situações nas quais os mercados não atingem por conta própria uma situação de eficiência econômica e o sistema de preços falha em sua função alocativa (PINDYCK; RUBINFELD, 2006).

As quatro principais razões para que ocorram fa- lhas de mercado, capazes de impedir que os mercados se apresentem de modo eficiente sob o ponto de vista econômico, são: poder de mercado existente nas mãos de produtores e/ou consumidores; assimetria de informação; presença de externalidades; ausência de certos bens públicos socialmente desejáveis (COOK, 1995). Uma das principais razões para a criação das cooperativas agropecuárias é a existência de falhas de mercado. Na mesma linha, Staatz (1987) aponta que, além das falhas de mercado, as cooperativas surgem quando a estrutura de governança coletiva se apresenta como a melhor solução.

A NEI engloba três campos de estudos organizacionais: a teoria dos direitos de propriedade, a teoria da agência e a economia dos custos de transação. Essas teorias estão interligadas por um conjunto de temas: a informação é cara, imperfeita e frequentemente assimétrica, a atribuição de direitos de propriedade afeta o desempenho econômico. Estruturas de governança podem ser concebidas para minimizar os custos de transação (SYKUTA; COOK, 2001).

Nas cooperativas, os cooperados possuem os direitos residuais ao fluxo de rendimento gerado pelo empreendimento (BIALOSKORSKI NETO, 2012). Entretanto, os direitos de propriedade sobre esse ativo são divididos entre um número elevado de pessoas, não existindo a separação completa, os proprietários não podem tomar posse dos fluxos oriundos desses direitos de forma completa, tornando-os difusos. Os direitos de propriedade difusos acabam por gerar problemas de governanças. Para uma melhor compreensão, na Seção 3.1, apresenta-se o ciclo de vida das organizações cooperativas, em que é possível identificar momentos em que os problemas de governança surgem, entre eles, o do portfólio.

\subsection{Ciclo de vida das cooperativas}

Um dos autores que buscou analisar o ciclo de vida das cooperativas agropecuárias foi Cook (1995). Na primeira fase do ciclo de vida, o autor sugere que os cooperados criam a cooperativa para atender aos seus interesses, com o objetivo de reduzir os problemas originados pelas falhas de mercado. Os cooperados sentem-se motivados a participar da organização. Na segunda fase, os cooperados delineiam a estrutura de governança da cooperativa, definindo a forma de controlar a organização e os direitos às sobras. As cooperativas que não conseguem se estruturar deixam o mercado.

$\mathrm{Na}$ terceira fase, a cooperativa expande suas atividades e a área de atuação para atender mais cooperados. $\mathrm{Na}$ sequência, investimentos são feitos em ativos específicos na relação cooperado-cooperativa (estruturas administrativa e de processamento, por exemplo), com aumento dos custos de transação, os preços da cooperativa não alteram significativamente dos demais concorrentes do mercado. É nessa fase que começam a surgir problemas de governança advindos dos direitos de propriedade

RGC - Vol. 01, Nº2, $2^{\circ}$ Sem. 2014, Págs. 51-62 
difusos, gerando problemas de fidelização, de investimento e de gestão. Algumas cooperativas não passam dessa fase, pois se tornam ineficientes e são eliminadas do mercado.

A quarta fase representa a análise sobre a cooperativa e os seus direitos de propriedade (às sobras e ao controle). A cooperativa precisa identificar novos mecanismos de incentivo ao investimento, bem como de controle da organização, devido à sua expansão. Assim, tem três escolhas: pode optar em sair do mercado, continuar com a estrutura de governança atual ou modificar a estrutura de propriedade.

A quinta fase se dá por meio da escolha de uma das alternativas da fase que a antecede. A cooperativa pode decidir sair do mercado, por meio da liquidação das atividades ou transformando-se em uma sociedade anônima. Se a opção for continuar com a estrutura de governança atual, faz-necessário rever sua estrutura de capital para continuar competitiva no mercado. Essa modificação na estrutura de capital pode ocorrer por meio da abertura do capital para membros investidores. Na Seção 3.2, apresenta-se o problema do portfólio que afeta o incentivo para que os cooperados invistam na sua organização.

\subsection{Problema do portfólio}

O problema do portfólio surge devido à impossibilidade dos cooperados ajustarem o seu portfólio de ativos na cooperativa, a fim de corresponder com as suas preferências de risco pessoal, devido a não transferência e liquidez e à falta de instrumentos financeiros de apreciação das cotas-partes nas cooperativas (COOK, 1995). Com isso, subgrupos de cooperados tendem a fazer pressão na organização para reorganizar o portfólio de investimentos da cooperativa, mesmo que um portfólio de menor risco implique retornos mais baixos para a organização (COOK; ILIOPOULOS, 1998).

Assim, o problema do portfólio surge, pois a cooperativa não é capaz de alinhar as suas estratégias de investimento e negócios às dos cooperados, devido à sua estrutura dos direitos de propriedade. Por outro lado, em organizações orientadas para o investidor, os investidores podem negociar ações para ajustar seus portfólios, a fim de alcançar níveis de risco de acordo com as suas preferências. Quanto mais semelhante é o portfólio ótimo da cooperativa e a preferência dos portfólios individuais dos cooperados, menor é o conflito entre o cooperado e a cooperativa (PLUNKETT, 2005).

O problema do portfólio está ligado às percepções sobre o risco e os negócios alternativos em que a cooperativa deveria se envolver. Com isso, o melhor portfólio para a cooperativa pode não ser o mesmo para todos os cooperados, ou seja, haverá cooperado atingindo o ótimo econômico e outros fora desse ponto. Há uma tendência de explorar projetos de menor risco e, consequentemente, de retorno menor, uma vez que o produtor rural não tem incentivo a assumir risco na cooperativa. $\mathrm{O}$ cooperado assume o risco em seu negócio, mas não suporta risco em sua cooperativa, exigindo resultados de curto prazo, muitas vezes, limitando um retorno maior da cooperativa no longo prazo (STAZZ, 1987).

Esse problema ocorre com maior frequência em cooperativas tradicionais, porque os membros investem na cooperativa na proporção do seu uso e as cotas de capital da cooperativa não podem ser compradas ou vendidas livremente (COOK, 1995). Portanto, os membros não são capazes de diversificar o seu portfólio individual de investimento, de acordo com a sua riqueza pessoal e as suas preferências para a tomada de decisões. A lei cooperativista brasileira proíbe a transação e a apreciação dos direitos de propriedade. Assim, os cooperados não podem remover ou realocar os seus investimentos e são forçados a aceitar riscos distintos daqueles que desejariam.

Plunkett (2005) identifica dois tipos de problemas de portfólio: o lateral e o vertical. O problema do portfólio lateral ocorre devido ao conflito entre cooperados especializados dentro de uma cooperativa diversificada. Membros altamente especializados tendem a preferir que a cooperativa reflita sua especialização na unidade de processamento, enquanto os cooperados que apresentam uma produção mais diversificada almejam que a cooperativa acompanhe essa diversificação. Alguns autores têm sugerido que as cooperativas funcionam de forma mais eficiente quando a heterogeneidade dos membros é baixa.

O problema do portfólio vertical ocorre devido ao conflito de estratégias de crescimento entre os cooperados de uma cooperativa especializada. Alguns cooperados preferem que a cooperativa pague um preço melhor pela commodity, já outros preferem que se tenha uma estratégia de sobras operacionais, para serem distribuídas aos cooperados.

\section{Metodologia}

Frente aos objetivos desta pesquisa, a ferramenta para coleta dos dados consistiu em roteiro semiestruturado. A primeira seção do questionário apresentou questões que visavam à caracterização das cooperativas analisadas. Na sequência, adotaram-se escalas métricas intervalares (cinco pontos) para medir a concordância dos entrevistados quanto ao problema do portfólio. A escala variou de um (não concordo totalmente), ou seja, ausência do problema na cooperativa analisada, até cinco (concordo totalmente), configurando a maior intensidade possível do problema na cooperativa. Posteriormente, foi utilizada uma questão qualitativa para captar a estratégia empregada pela cooperativa para minimizar o problema do portfólio. Os respondentes foram gestores 
e presidentes das cooperativas amostradas.

Após a construção do roteiro, realizou-se a definição da amostra. A primeira etapa foi verificar qual a população real (ativa) de cooperativas agropecuárias no Rio Grande do Sul. Para isso, utilizou-se a lista de cooperativas agropecuárias ligadas à Organização das Cooperativas do Rio Grande do Sul (OCERGS), em que constavam 170 cooperativas agropecuárias singulares (embora nem todas ativas). Com isso, buscou-se, por meio de informações, excluir da população as cooperativas inativas ou em processo de liquidação, recorrendo a informações da OCERGS e da Federação das Cooperativas Agropecuárias do Rio Grande do Sul (FECOAGRO), por meio de contato com profissionais da área e com algumas cooperativas.

Com base no exposto, elaborou-se a Tabela 1, em que podem ser visualizados os seis grupos de cooperativas resultantes da estratificação da população (de cooperativas singulares ativas do RS ligadas à OCERGS) por atuação, de acordo com o recebimento de matéria-prima, bem como em pequeno, médio ou grande porte. Ressalta-se que não se incluiu na população a ser amostrada as cooperativas associadas à União Nacional das Cooperativas de Agricultura Familiar e Economia Solidária (UNICAFES). processamento e à comercialização de frutas e hortaliças. No Grupo 5 estão as cooperativas de produtos orgânicos, que comercializam e processam frutas e olerícolas, entretanto, apresentam especificidades que justificam a segmentação em um grupo distinto do 4 . No Grupo 6 estão as "outras" cooperativas, pois não apresentam número suficiente de cooperativas para constituir um grupo individual. Entre elas estão cooperativas de apicultores, do setor florestal e de produtores de lã.

Quanto ao tamanho da cooperativa, o critério de estratificação foi o número de cooperados. Foram definidos três portes de cooperativas: i) pequeno porte: até 999 cooperados; ii) médio porte: de 1000 a 2999 cooperados; i) grande porte: acima de 3000 cooperados.

Em razão do período para a execução da pesquisa e do limite de recursos disponíveis, o critério definido foi o de amostrar $10 \%$ das cooperativas agropecuárias do RS ligadas à OCERGS. Buscou-se manter a proporcionalidade entre os grupos e os portes na amostragem (Tabela 2), em um total de 16 cooperativas amostradas.

Para a realização das entrevistas, foi estabelecido que o respondente fosse um representante da cooperativa com um adequado conhecimento da organização. Esse indivíduo poderia ser um gestor ou integrante da direção (presidente ou vice-presidente) ou um dos dois

Tabela 1 - Número total de cooperativas agropecuárias singulares ativas no Rio Grande do Sul e estratificação por grupo de atuação e porte

\begin{tabular}{llcccc}
\hline Grupo & Pequeno porte & Médio porte & Grande porte & Total \\
\hline 1 & Grãos & 57 & 11 & 23 & 91 \\
2 & Leite, suínos, aves & 6 & 2 & 6 & 14 \\
3 & Vitivinícola & 13 & 1 & 0 & 14 \\
4 & Frutas e olerícolas & 10 & 0 & 1 & 11 \\
5 & Produtos orgânicos & 12 & 1 & 0 & 13 \\
6 & Outras (apicultores, florestal, lã) & 11 & 0 & 0 & 11 \\
\hline Total & 109 & 15 & 30 & 154 \\
\hline
\end{tabular}

Fonte: Elaborada pelos autores com base nos dados da pesquisa.

Para a cooperativa ser enquadrada no Grupo 1, os grãos devem ser a principal fonte do faturamento da cooperativa (seja de forma direta por meio da comercialização ou a partir do fornecimento de insumos para os cooperados). No Grupo 2 estão as cooperativas que têm como principal faturamento atividades ligadas ao processamento de leite, suínos e aves. Cumpre ressaltar que algumas dessas cooperativas possuem grãos como atividade, entretanto, não sendo a principal atividade de negócio.

No Grupo 3 estão as cooperativas vitivinícolas. O Grupo 4 é composto por cooperativas que se dedicam ao que tivesse exercido mandato nos últimos cinco anos. A pesquisa de campo foi realizada entre 04 de julho e 08 de agosto de 2012 nas sedes das cooperativas, por meio da aplicação in loco do roteiro semiestruturado pelo pesquisador.

\section{Resultados e discussão}

O maior período de fundação das cooperativas analisadas foi de 1970 a 2010 (43,75\%). Essas são cooperativas de grãos de pequeno porte, de produtores de maçã e de 
Tabela 2 - Cooperativas amostradas por grupos de atuação e porte

\begin{tabular}{lccrrrr}
\hline \multicolumn{1}{c}{ Grupo } & $\begin{array}{c}\text { Amostragem } \\
\mathbf{( 1 0 \% )}\end{array}$ & $\begin{array}{c}\text { Total de } \\
\text { cooperativas }\end{array}$ & \multicolumn{4}{c}{ Amostradas } \\
\cline { 4 - 7 } & & & $\begin{array}{c}\text { Pequeno } \\
\text { porte }\end{array}$ & $\begin{array}{c}\text { Médio } \\
\text { porte }\end{array}$ & $\begin{array}{c}\text { Grande } \\
\text { porte }\end{array}$ & Total \\
\hline 1 Grãos & 9,1 & 91 & 6 & 1 & 2 & 9 \\
2 Leite, suínos, aves & 1,4 & 14 & 1 & 1 & 1 & 3 \\
3 Vitivinícola & 1,4 & 14 & 1 & 0 & 0 & 1 \\
4 Frutas e olerícolas & 1,1 & 11 & 1 & 0 & 0 & 1 \\
5 Produtos orgânicos & 1,3 & 13 & 1 & 0 & 0 & 1 \\
$\quad$ Outras (apicultores, & 1,1 & 11 & 1 & & & \\
6 florestal, lã) & 15,4 & 154 & 11 & 2 & 3 & 1 \\
\hline \multicolumn{1}{c}{ Total } & & & & & & \\
\hline
\end{tabular}

Fonte: Elaborado pelos autores com base nos dados da pesquisa.

ecológicos, bem como de armazenamento de leite. O principal objetivo apontado pelos entrevistados, para a formação dessas organizações, está ligado ao aumento do poder de barganha junto aos mercados por parte dos produtores rurais. $\mathrm{O}$ mercado em que essas cooperativas atuam estava concentrado em uma ou poucas empresas compradoras da produção. Esses resultados confirmam a discussão de Cook (1995), sobre as motivações iniciais que levam à formação de uma cooperativa.

Em segundo lugar estão as cooperativas que foram fundadas no período de 1940 a 1970 (37,50\%), formadas em um momento de incentivo governamental para a modernização da agricultura. Entre elas estão as cooperativas de grãos de maior porte e algumas de médio porte, bem como uma representante do setor de lã.

Em terceiro lugar estão as cooperativas fundadas entre 1910 e 1940 (18,75\%). Essas tiveram início com os primeiros imigrantes europeus (italianos e alemães principalmente). As representantes desse período são cooperativas de suinocultores, produtores de leite e vitivinicultores, com grande diferenciação de produtos, ou seja, transformam a matéria-prima em um grande número de produtos finais (agregação de valor).

Nota-se, na Tabela 3, a variabilidade das cooperativas amostradas. Optou-se por não apresentar as médias das variáveis na caracterização, visto que a amostra foi intencional, explorando a diversidade do cooperativismo no RS.

Com base na Tabela 3, das 16 cooperativas analisadas, cinco apresentaram variação negativa no número de cooperados de 2000 para 2010, tendo diversas causas para tal variação. Duas das cooperativas reduziram o número de cooperados por fatores ligados à atividade de negócios, nas quais as cooperativas estão inseridas. $\mathrm{Na}$ cooperativa 2 (setor) orizícola, a redução $(-50 \%)$ ocorreu, de acordo com o entrevistado, devido à saída de muitos produtores da atividade, por não apresentarem uma escala adequada, ocorrendo um aumento da área média dos cooperados remanescentes. A cooperativa 11, ligada à suinocultura, apresentou uma redução no número de cooperados (-39\%) em razão de sucessivas crises (baixo preço pago pelo suíno e aumento dos custos de produção) que a atividade enfrentou. Como consequência, muitos produtores optaram por deixar a atividade.

A cooperativa 6 apresentou redução $(67 \%)$ do quadro social em razão da exclusão de cooperados, da mesma forma que a cooperativa $8(12 \%)$, a qual realizou o desligamento dos cooperados com os quais não transacionava de 2000 a 2010. A cooperativa 10 apresentou redução (11\%) no número de cooperados, devido à saída daqueles que participaram da sua fundação, por motivos diversos.

A maior parte das cooperativas analisadas obteve um aumento no quadro social. A cooperativa 1 , fundada na década de 1990, teve como política buscar novos cooperados, ou seja, não ficar aguardando que o cooperado fosse até a cooperativa para se associar, mas sim alocando uma equipe para atraí-los. Essa conduta mais agressiva da cooperativa está relacionada à estrutura de mercado da região, com a entrada de um número maior de empresas que processam a matéria-prima recebida pela cooperativa, aumentando a competição e a disputa pelos produtores rurais. A cooperativa sentiu a necessidade de aumentar a escala da organização para oferecer benefícios aos produtores e não perder espaço para as empresas da região. As variações positivas mais expressivas no número de cooperados ocorreram nas cooperativas fundadas após a década de 1990, como o 
Tabela 3 - Variáveis descritivas do perfil das cooperativas amostradas

\begin{tabular}{|c|c|c|c|c|c|c|c|}
\hline $\begin{array}{l}\text { Área de } \\
\text { atuação }\end{array}$ & Porte $^{1}$ & Cooperativa & $\begin{array}{l}\text { Número de } \\
\text { cooperados } \\
(2011)\end{array}$ & $\begin{array}{l}\text { Número de } \\
\text { empregados } \\
\text { (2011) }\end{array}$ & $\begin{array}{l}\text { Variação no } \\
\text { número de } \\
\text { cooperados } \\
(2000-2010)\end{array}$ & $\begin{array}{l}\text { Faturamento em } \\
\text { milhões de reais } \\
\qquad(2011)\end{array}$ & $\begin{array}{c}\text { Número } \\
\text { de } \\
\text { técnicos } \\
\text { (2011) }\end{array}$ \\
\hline Grãos & $\mathrm{P}$ & 1 & 940 & 95 & $138 \%$ & $\mathrm{R} \$ 135.000 .000,00$ & 15 \\
\hline Grãos & $\mathrm{P}$ & 2 & 600 & 420 & $-50 \%$ & $\mathrm{R} \$ 130.000 .000,00$ & 11 \\
\hline Grãos & $\mathrm{P}$ & 3 & 700 & 9 & $75 \%$ & $\mathrm{R} \$ 13.000 .000,00$ & 1 \\
\hline Grãos & $\mathrm{P}$ & 4 & 400 & 16 & $900 \%$ & $\mathrm{R} \$ 18.000 .000,00$ & 3 \\
\hline Grãos & $\mathrm{P}$ & 5 & 600 & 50 & $5.355 \%$ & Não disponibilizado & 20 \\
\hline Grãos & $\mathrm{P}$ & 6 & 32 & 97 & $-67 \%$ & $\mathrm{R} \$ 24.000 .000,00$ & 2 \\
\hline Grãos & M & 7 & 2.070 & 86 & $1 \%$ & $\mathrm{R} \$ 41.000 .000,00$ & 4 \\
\hline Grãos & G & 8 & 11.600 & 709 & $-12 \%$ & $\mathrm{R} \$ 429.738 .930,00$ & 33 \\
\hline Grãos & G & 9 & 5.200 & 300 & $50 \%$ & $\mathrm{R} \$ 240.000 .000,00$ & 15 \\
\hline Leite & $\mathrm{P}$ & 10 & 178 & 7 & $-11 \%$ & $\mathrm{R} \$ 4.020 .000,00$ & 2 \\
\hline Suíno & M & 11 & 1.530 & 530 & $-39 \%$ & $\mathrm{R} \$ 135.000 .000,00$ & 8 \\
\hline $\begin{array}{l}\text { Leite e } \\
\text { suínos }\end{array}$ & G & 12 & 4.300 & 1.350 & $33 \%$ & $\mathrm{R} \$ 500.000 .000,00$ & 72 \\
\hline Vitivinícola & $\mathrm{P}$ & 13 & 400 & 24 & $25 \%$ & $\mathrm{R} \$ 18.000 .000,00$ & 6 \\
\hline Frutas & $\mathrm{P}$ & 14 & 41 & 116 & - & $\mathrm{R} \$ 32.000 .000,00$ & 1 \\
\hline $\begin{array}{l}\text { Produtos } \\
\text { ecológicos }\end{array}$ & $\mathrm{P}$ & 15 & 24 & 2 & $0 \%$ & $\mathrm{R} \$ 1.900 .000,00$ & 1 \\
\hline \multirow[t]{2}{*}{ Lã } & $\mathrm{P}$ & 16 & 840 & 9 & $100 \%$ & $\mathrm{R} \$ 3.000 .000,00$ & 1 \\
\hline & & Total & 29.455 & 3.820 & & $\mathrm{R} \$ 1.724 .658 .930,00$ & 195 \\
\hline
\end{tabular}

Fonte: Elaborada pelos autores com base nos dados da pesquisa. Nota: ${ }^{1}$ Pequeno (P); Médio (M); Grande (G).

caso da cooperativa 5.

O problema do portfólio apresentou uma média de concordância de 1,938 (intervalo entre 1 e 5), como se visualiza na Tabela 4. Esse problema ocorre, pois os membros são impedidos de ajustar o seu portfólio de ativos na cooperativa às suas preferências de risco pessoal, devido às decisões serem igualitárias, a não transferência, à falta de liquidez e à apreciação da cota-parte nas cooperativas, como é discutido em Cook (1995). Esse problema teve maior incidência nas cooperativas que processam ou transformam a matéria-prima, pois há um maior número de projetos e investimentos que podem gerar conflitos.

A variável que apresentou maior valor no problema do portfólio foi a 3 ("alguns cooperados pressionam a cooperativa por investimentos de menor risco, mesmo que esses investimentos reduzam o retorno da cooperativa"), com média de 2,688. Oito cooperativas apresentaram resultados altos (superiores a 3 para a variável). Por outro lado, essa pressão dos cooperados não resulta em abandono de projetos por parte das cooperativas, como pode ser observado na média da variável 4 ("o conselho de administração e de gestores deixam de realizar projetos ou investimento que têm um maior retorno para a cooperativa, devido às preferências individuais dos cooperados"), com média de 1,250, uma das mais baixas entre as afirmativas.

A segunda variável com média mais elevada foi a 2 ("é comum os cooperados relatarem o descontentamento com as escolhas de projetos e investimentos feitas pelos gestores ou pelo conselho de administração da cooperativa, comentando que suas preferências individuais quanto a essas escolhas eram outras") com média de 2,438 . Cumpre ressaltar que a variável 1 expressa que "os cooperados apresentam resistência em aprovar projetos em bens intangíveis (marcas de produtos e marketing)".

Na Figura 1, visualizam-se os valores de concordância com o problema do portfólio por cooperativa. Nota-se que a média mais alta $(3,800)$ foi observada na cooperativa 15, que reúne produtores de produtos orgânicos. Essa média deve-se a conflitos que ocorreram durante a sua 
Tabela 4 - Estatísticas descritivas (média, desvio-padrão e coeficiente de variação) por variáveis no problema do portfólio

\begin{tabular}{cccccccc}
\hline \multicolumn{6}{c}{ Variável } & & \multicolumn{3}{c}{ Problema } \\
\hline & Variável & Média & Desvio & CV (\%) & Média & Desvio & CV (\%) \\
\hline \multirow{4}{*}{ Portfólio } & $\mathbf{1}$ & 1,375 & 0,885 & $64,37 \%$ & & & \\
& $\mathbf{2}$ & 2,438 & 1,590 & $65,24 \%$ & 1,938 & 0,731 & $37,71 \%$ \\
& $\mathbf{3}$ & 2,688 & 1,887 & $70,23 \%$ & & & \\
\hline
\end{tabular}

Fonte: Elaborada pelos autores com base nos dados da pesquisa.

trajetória, em que os interesses da organização foram conflitados com os dos cooperados. Os gestores queriam investir em projetos de maior risco para a cooperativa, visando à expansão da organização, entretanto, foram impedidos pelos cooperados. cooperados têm essa consciência".

Em algumas cooperativas foi constatada a resistência dos cooperados em investir em novos projetos. O entrevistado da cooperativa 13 mencionou que a expressão "sempre deu certo, por que mudar?" é comumente

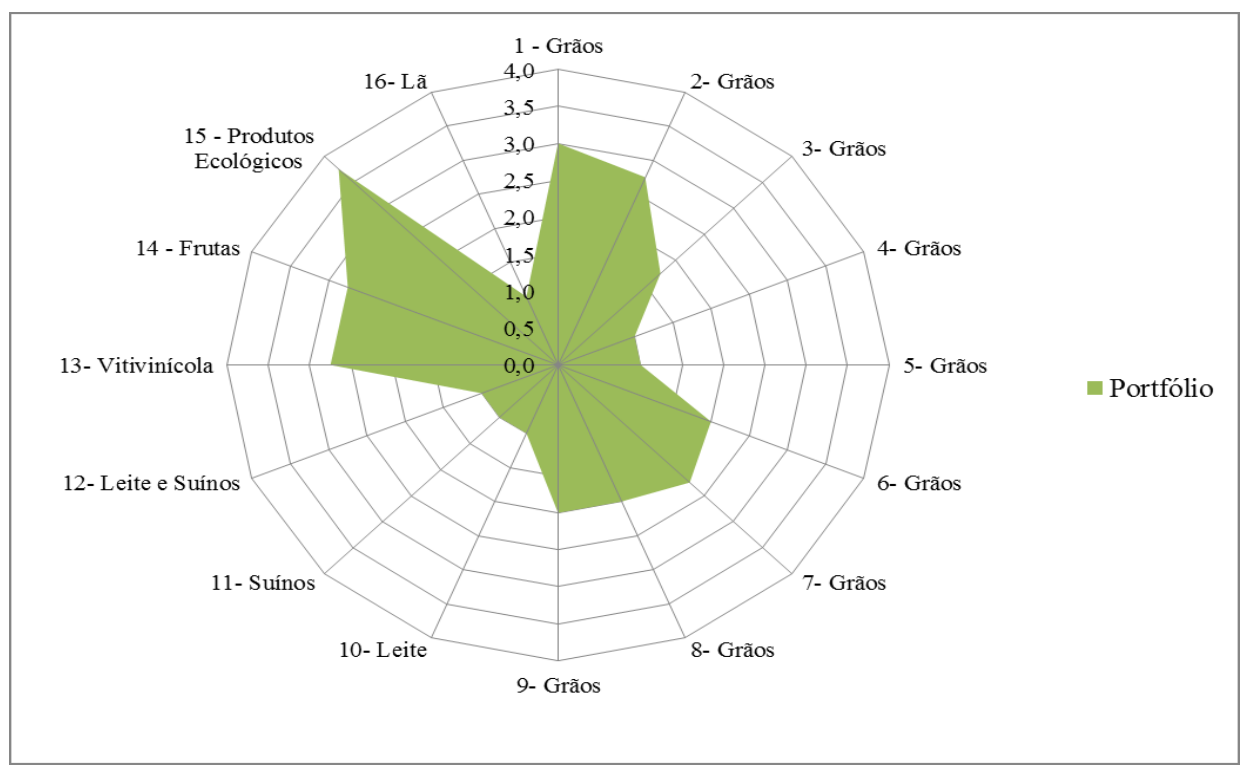

Figura 1 - Concordância dos entrevistados para o problema do portfólio nas 16 cooperativas, por meio do valor médio das quatro variáveis analisadas

Fonte: Elaborada pelos autores com base nos dados da pesquisa.

Não foram relatados problemas em aprovar projetos de marketing e de diferenciação de produtos. Nas cooperativas 11 e 12, foi relatado que possuem apoio dos cooperados para realizar investimentos em marketing e desenvolvimento de produtos. Segundo o entrevistado da cooperativa 11, "os projetos de investimento e de diferenciação de produtos não são rejeitados pelos cooperados, visto que é a principal estratégia para fugir do mercado de cortes tradicionais de carne suína e os mencionada na organização, evidenciando a resistência à inovação. Entretanto, para o entrevistado, essa resistência tem reduzido nos últimos anos e, em virtude da inserção da informática no meio rural, os produtores estão mais abertos e receptivos a novos projetos e a investimentos do que no passado.

Buscou-se compreender as estratégias das cooperativas nas escolhas dos projetos e investimentos a serem realizados pela organização, a relação risco-retorno, a 
diversificação e interesse dos cooperados nos projetos. As principais estratégias empregadas pelas cooperativas, visando à redução do problema do portfólio, foram: escolha dos projetos de investimentos com base no mercado, avaliação técnica dos projetos e investimentos, opção pelo não crescimento da cooperativa, composição do conselho para evitar problemas de portfólio lateral.

$\mathrm{Na}$ maioria das cooperativas pesquisadas, o entrevistado relatou que os investimentos e os projetos feitos pela cooperativa buscam a minimização do risco. Um dos primeiros pontos analisados relacionou-se ao crescimento das cooperativas. Verificou-se que existe receio em optar por estratégias de crescimento nas cooperativas agropecuárias, devido às crises que o cooperativismo já enfrentou. O entrevistado de uma das cooperativas de pequeno porte de grãos relatou que a cooperativa é muito cautelosa quanto à expansão. Existe uma percepção dos dirigentes da cooperativa (com base no histórico do cooperativismo no estado) de que organizações que cresceram mais apresentaram uma dificuldade superior em sua gestão, o que levou muitas cooperativas a entrarem em processo de liquidação. Essa é uma situação presente na discussão econômica sobre o tamanho da firma.

Entretanto, nos últimos anos, devido à forte concorrência no mercado de grãos, com grandes empresas que estão na área de atuação da cooperativa, a conduta da organização está mais agressiva, buscando captar novos cooperados, projetos e investimentos, tendo em vista o aumento da escala e fazendo frente a essas empresas. Esse processo faz parte do ciclo de vida das cooperativas, conforme descrito por Cook (1995).

Algumas cooperativas não pretendem expandir sua área de atuação, como o exemplo da cooperativa 10, para não aumentar a complexidade organizacional e os problemas de governança. Por outro lado, a cooperativa 12 (de grande porte e do grupo de leite e suínos) está buscando a expansão para áreas mais agrícolas. De acordo com o entrevistado, algumas das cooperativas da região ficaram concentradas em áreas que estão sendo urbanizadas. A cooperativa tem buscado expandir para áreas agrícolas, com características de pequena propriedade, a fim de superar esse problema. Das 16 cooperativas analisadas, três pretendem expandir para novas áreas de atuação e quatro visam aumentar a escala de produção.

Analisando a escolha dos investimentos pelas cooperativas, um entrevistado relatou que a sua organização (pequeno porte na área de grãos) seleciona os projetos de investimentos com base no mercado, o que não é frequente nas cooperativas desse grupo. Quando existe o interesse de uma determinada área e se visualiza que existe a possibilidade de retorno, ocorre a expansão para outras áreas. Os projetos de expansão são bem planejados para reduzir o risco do empreendimento não ser bem sucedido economicamente.

Quanto ao conflito com o interesse individual dos cooperados, um dos entrevistados (de uma cooperativa de grande porte de grãos) afirmou que não se submete à pressão dos cooperados, fazendo sempre que possível uma avaliação técnica dos projetos e investimentos a serem realizados. Atualmente, a cooperativa está buscando uma estratégia de maior risco, com objetivo de ampliar a margem de sobras operacionais da organização, devido à necessidade de retorno financeiro maior e de capitalização. Entre as ações, está a implementação de uma central de compras (supermercados e parte de insumos), em parceira com outras cooperativas, para aumentar o retorno dessa atividade de negócio.

Na cooperativa 9 (grupo grãos de grande porte), verificou-se a presença do problema do portfólio lateral, ou seja, entre os cooperados com diferentes atividades produtivas na cooperativa. De acordo com o entrevistado, os produtores de soja tentam aprovar projetos e investimentos em seu favor, da mesma forma que os de arroz e de leite. Para mitigar esse problema, a cooperativa segmenta o número de membros do conselho de acordo com a atividade produtiva, proporcionalmente ao número de cooperados em cada atividade.

Em cooperativas agropecuárias com modelo tradicional, o acesso ao capital de risco é restrito. As formas adotadas para capitalizar a cooperativa são via taxa de associação do cooperado, retenção de lucros e financiamentos bancários. A arquitetura organizacional da cooperativa não gera incentivos aos cooperados para a sua capitalização, uma vez que a cota-parte não apresenta mercado secundário desenvolvido e as sobras operacionais são repartidas de acordo com a movimentação do cooperado em termos de compra/venda de produtos, ou seja, do seu volume de transação com a cooperativa.

Muitas cooperativas limitam o financiamento de projetos com recursos próprios.

A opção pelo menor crescimento pode representar menores custos de controle e menores perdas residuais trazidas pelo problema do controle e custos de influência. Além disso, uma baixa escala de operação tende a facilitar o processo de monitoramento por parte dos cooperados e a propiciar um maior alinhamento de interesses, favorecendo a tomada de decisão coletiva. Por essa razão, é comum o argumento que o crescimento da cooperativa é uma das principais causas do aumento dos problemas de governança em cooperativas (COOK, 1995). O não crescimento da organização cooperativa apresenta-se como uma estratégia para minimizar os problemas do portfólio.

Bialoskorski Neto (1998) corrobora com o exposto. Para o autor, a organização cooperativa apresenta maior viabilidade quando é menor e com baixa especificidade de ativos, devido ao custo de oportunidade do capital próprio e os custos da estrutura de governança financeira. O processo necessário para o crescimento da firma faz aumentar os custos de transação e da agência. Logo, cooperativas de menor porte possivelmente têm menores problemas do portfólio, podendo a opção pelo não 
crescimento da organização ser uma estratégia viável.

Por outro lado, a necessidade de escala para fazer frente às demais organizações que atuam no agronegócio faz com que as cooperativas sejam pressionadas a aumentar o seu porte, para continuarem competitivas. Nesse contexto, existe um trade-off, crescer e estar submetido ao aumento da complexidade gerencial ou permanecer pequeno e ter um menor poder de mercado frente às grandes organizações do setor.

Nos Estados Unidos, os contratos formais e as estratégias financeiras (ações, por exemplo) ajudam a minimizar e a resolver os problemas do portfólio (COOK; ILIOPOULOS, 1998). Outra estratégia para minimizar o problema do horizonte é a distribuição de sobras operacionais aos cooperados. Há poucas estratégias na literatura para minimizar o problema do portfólio em cooperativas com modelos tradicionais. A maioria das estratégias está ligada aos novos modelos organizacionais, o que implica em mudança nos direitos de propriedade.

\section{Conclusões}

O problema do portfólio manifestou-se principalmente em cooperativas que processam a sua produção. Identificou-se que a escolha de projetos e investimentos com base no mercado e a avaliação técnica dos mesmos pode reduzir o conflito entre as preferências da organização e dos cooperados.

Os novos modelos organizacionais, que modificam os direitos de propriedade nas cooperativas, estão sendo utilizados em outros países e permitem que o cooperado visualize mais claramente a sua dimensão de proprietário dentro da cooperativa, investindo e deixando de ser um simples usuário dos serviços da organização. $\mathrm{O}$ cooperativismo agropecuário brasileiro e, em especial, do Rio Grande do Sul pode pensar em formas de se apropriar desses modelos, buscando compatibilizar os princípios cooperativistas para tornar as cooperativas mais adaptadas ao contexto do século XXI.

Problemas de governança são comuns em qualquer tipo de estrutura. No entanto, cabe às cooperativas estarem cada vez mais adaptadas aos desafios que são impostos em relação ao crescimento e ao aumento da complexidade gerencial; ou permanecerão pequenas com um menor poder de mercado frente às grandes organizações do setor. Em estudos futuros, pode-se aumentar o número de variáveis a serem analisadas para o problema do portfólio.

\section{Referências}

BIALOSKORSKI NETO, S. Cooperativas: economia, crescimento e estrutura de capital. 1998. Tese (Doutorado em Economia Aplicada) - Universidade de São Paulo, São Paulo, 1998.

Economia e gestão de organizações

cooperativas. São Paulo: Atlas, 2012.

BRASIL. Lei no 5.764, de 16 de dezembro de 1971. Define a Política Nacional de Cooperativismo, institui o regime jurídico das sociedades cooperativas, e dá outras providências. Brasília, DOU, 1971. Disponível em: <http://www.planalto. gov.br/

ccivil_03/leis/L5764.htm>. Acesso em: 23 set. 2014.

COASE, R. H. The nature of the firm. Economica, v. 4, n. 16, pp. 386-405, 1937.

COMMONS, J. R. Institutional economics. American Economic Review, v. 21, n. 4, pp. 648-657, 1931.

COOK, M. L. The future of US agricultural cooperatives: a neo-institucional approach. American Journal of Agricultural Economics, v. 77, pp. 1153-1159, 1995.

COOK, M. L.; ILIOPOULOS, C. Solutions to property rights constraints in producer-owned and controlled organizations: prerequisite for agri-chain leadership?. In: ZIGGERS, G. W.; TRIENEKENS, J. H.; ZUURBIER, P. J. P. (Eds.). Proceedings of the third international conference on chain management in agribusiness and the food industry. Wageningen: Wageningen Agricultural University, 1998. p. 541-553.

PLUNKETT, B. The portfolio problem in agricultural cooperatives: an integrated framework. 2005. Tese (Doutorado em Economia Agrícola) - Universidade de Missouri, Columbia, Estados Unidos da América, 2005.

PINDYCK, R. S.; RUBINFELD, D. L. Microeconomia. São Paulo: Prentice Hall, 2006.

PIVOTO, D. et al. Análise do perfil financeiro e estrutural das cooperativas agropecuárias do Estado do Rio Grande do Sul. Ensaios FEE, v. 35, n. 1, p. 249-266, 2014.

STAATZ, J. M. The structural characteristics of farmers cooperatives and their behavioral consequences. Washington: USDA, 1987.

SYKUTA, M. E.; COOK, M. L. A new institutional economics approach to contracts and cooperatives. American Journal of Agricultural Economics, v. 83, 
n. 5, 2001.

VALADARES, J. H. A moderna administração de cooperativas: curso de preparação para os futuros dirigentes da Unimed-RO. Porto Velho: FGV, 2001. 
